\title{
Development and Evaluation of Insulin Incorporated Nanoparticles for Oral Administration
}

\author{
Amiya kumar Prusty ${ }^{1}$ and Susanta Kumar Sahu ${ }^{2}$ \\ ${ }^{1}$ Institute of Pharmacy and Technology, Salipur, Cuttack, Odisha 754 202, India \\ ${ }^{2}$ University Department of Pharmaceutical Sciences, Utkal University, Bhubaneswar, Odisha, India \\ Correspondence should be addressed to Amiya kumar Prusty; amiyaprusty@gmail.com
}

Received 15 May 2013; Accepted 27 June 2013

Academic Editors: K. H. Park, Z. Shi, and H. Tang

Copyright (C) 2013 A. K. Prusty and S. K. Sahu. This is an open access article distributed under the Creative Commons Attribution License, which permits unrestricted use, distribution, and reproduction in any medium, provided the original work is properly cited.

\begin{abstract}
The current study was designed to prepare and characterize insulin incorporated nanoparticles by complex coacervation process followed by antidiabetic study of orally administered insulin incorporated nanoparticles in diabetic rats. The nanoparticles were characterized for particle size, loading and entrapment efficiency as well as in vitro release of incorporated insulin. The prepared nanoparticles were found to have an average particle size of $551.67 \mathrm{~nm} \pm 45.5$. The highest entrapment efficiency and loading capacity values were found to be of $52.48 \pm 1.98$ and $47.01 \pm 1.21$, respectively. Oral administration of $10 \mathrm{IU} / \mathrm{Kg}$ of insulin loaded nanoparticles to diabetic rats showed a maximum blood glucose change of $53.46 \pm 2.19$ at 5 -hours time period. The results obtained indicate the potential of prepared nanoparticulate system as a carrier for oral delivery of insulin.
\end{abstract}

\section{Introduction}

Oral route is considered to be more convenient, safe, and most the acceptable route of administration of drugs for chronic therapy. In the treatment of insulin dependent diabetes mellitus or type-1 diabetes, insulin is generally administered parenterally via subcutaneous route. But this clinical therapy suffers from many disadvantages, for example, local discomfort, inconvenience of multiple administration, and occasional hyperinsulinemia due to overdose [1]. However insulin administered by oral route is not as effective as by subcutaneous route because of poor absorption in gastrointestinal tract because of it's large size and hydrophilic nature. Insulin due to proteinaceous in nature is degraded by gastric acid or proteolytic enzymes present in GI tract that act as the most important barrier limiting the absorption of insulin [2]. Therefore numbers of research are carried out to administer and make insulin available orally for treatment of Diabetes.

Entrapment of insulin within the nanoparticulate carrier system is a very good approach to increase the bioavailability of insulin after oral administration. The nanoparticulate carrier system is protecting insulin from the digestive enzymes in GI-tract. In the present research the nanoparticles are prepared by using two hydrophilic biodegradable polymers chitosan and alginate. Chitosan is a natural cationic polysaccharide derived from deacetylation of chitin, which is, after cellulose, the most abundant polymer found in nature. It is hydrophilic, biocompatible, and biodegradable in nature [3]. Because of its bioadhesive property, chitosan has also received substantial attention in novel bioadhesive drug delivery systems with the aim to improve the bioavailability of drugs by prolonging the residence time at the site of absorption [4]. Chitosan can induce a redistribution of cytoskeletal $\mathrm{F}$-actin and the tight junction protein $\mathrm{ZO}-1$ via interaction between its positive charges and mucosal negative charges, which results in increased paracellular permeability of hydrophilic macromolecules [5]. Alginates are extracted from three species of brown algae, Laminaria hyperborean, Ascophyllum nodosum, and Macrocystis pyrifera. Alginate is a water-soluble linear polysaccharide composed of alternating blocks of 1-4 linked $\alpha$-L-guluronic and $\beta$-Dmannuronic acid. It is also hydrophilic, biocompatible, and biodegradable in nature. The relatively mild gelation process of alginate helps in entrapment of proteins, cells, and DNA with retention of full biological activity [6]. The nanoparticles 
were prepared by complex coacervation technique. Coacervation is a process during which a homogeneous solution of charged macromolecules undergoes liquid-liquid phase separation, producing a polymer rich dense phase. Two oppositely charged macromolecules can undergo complex coacervation through electrostatic and additional interactions. Coacervation has been widely applied to protein purification and drug delivery. Complex coacervation can be spontaneously formed upon mixing oppositely charged polymers in aqueous media. Protein-protein, protein-polysaccharide, and polysaccharide-polysaccharide combinations have been frequently studied for drug delivery and biomedical applications. In the present study, a physical combinational gel, not chemically cross-linked, was hypothesized to be formed by adding two oppositely charged bio macromolecules composed of natural polysaccharides, which results in complex coacervation. This technique involves simple and mild preparation method in the aqueous environment thereby keeping the sensitive protein drug insulin stable. The prepared insulin incorporated nanoparticles are characterized for different factors like particle size, shape, insulin entrapment, loading and release, and so forth. Finally the antidiabetic efficacy of insulin incorporated nanoparticles is evaluated after oral administration to diabetic rats [7].

\section{Materials and Methods}

2.1. Materials. Low molecular weight chitosan $(50 \mathrm{KDa})$ was procured from Aldrich, USA. Low viscosity sodium alginate was procured from Sigma, USA. Streptozotocin was procured from Sisco Research laboratories Pvt. Ltd., India. Human insulin of recombinant DNA origin was obtained from Eli Lilly and Company, India. Human Insulin injection (Wosulin-R), Wockhardt Pvt. Ltd., India, was procured from local medicine shop. HPLC grade acetonitrile, hydrochloric acid, phosphoric acid, and water were obtained from Merck, India. Human insulin ELISA kit, Millipore, all other solvents, and materials used were of analytical grade.

2.2. Experimental Animals. Adult albino rats of either sex weighing between 150 and 250 gm were used in the present investigation. Before initiation of the experiment, the rats were acclimatized for a period of 7 days. Standard environmental conditions such as temperature $\left(30 \pm 2^{\circ} \mathrm{C}\right)$, relative humidity (45-55\%), and 12-hour dark/light cycles were maintained in the quarantine. All the animals were fed with rodent pellet diet (Gold mohr, Lipton India Ltd.) and water was allowed ad-libitum under strict hygienic conditions. The experiment was carried out after due certification (Approval no. 03/IAEC-IPT/09) from animal ethical committee and abiding to strict rules and regulations of the committee.

\subsection{Methods}

2.3.1. Preparation of Insulin Loaded Nanoparticles. $10 \mathrm{IU}$ concentration of insulin was added to $5 \mathrm{~mL}$ of $0.1 \% \mathrm{w} / \mathrm{v}$ chitosan solution with continuous stirring in a magnetic stirrer followed by addition of $2 \mathrm{~mL}$ of $0.1 \% \mathrm{w} / \mathrm{v}$ sodium alginate solution at room temperature for 30 mins. The reaction mixture was centrifuged at $15000 \mathrm{rpm}$ at $4^{\circ} \mathrm{C}$ for 15 mins. The supernatant was decanted and nanoparticles were suspended in sterile distilled water and recentrifuged at $15000 \mathrm{rpm}$ at $4^{\circ} \mathrm{C}$ for 15 mins to separate the nanoparticles [8].

2.3.2. Physicochemical Characterization. The prepared nanoparticles were lyophilized and different physicochemical characteristics were analyzed. The particle size was determined using a Zetasizer, Nano-ZS (Malvern Instruments, Malvern, UK). The measurement was carried out in disposable polystyrene cuvettes at $25^{\circ} \mathrm{C}$ with detection angle of $90^{\circ}$ and by adjusting the viscosity and refractive index as that of water at $0.8872 \mathrm{cP}$ and 1.33 , respectively. The morphological examination of the nanoparticles was performed by scanning electron microscopy (SEM) using Hitachi S4800 [2]. The FT-IR spectra of insulin loaded nanoparticles and pure insulin were determined using a Shimadzu 8400S, FT-IR spectrophotometer [9].

2.3.3. Determination of Loading and Entrapment Efficiency. To determine the suitability of the nanoparticulate system to act as a carrier for insulin, determination of loading percentage and entrapment efficiency of insulin in the nanoparticulate system was very essential. The amount of free insulin in the supernatant was determined by HPLC (Shimadzu LC-10A, Kyoto, Japan) equipped with a UV detector (Shimadzu SPD-10A) and phenomenex gemini-C18 column. The mobile phase used was a mixture of acetonitrile: $0.1 \mathrm{M}$ $\mathrm{NaH}_{2} \mathrm{PO}_{4}: 0.05 \mathrm{M} \mathrm{Na}_{2} \mathrm{SO}_{4}=30: 35: 35$ ( $\mathrm{pH}$ was adjusted to 3 by phosphoric acid). The flow rate was maintained at $1 \mathrm{~mL} / \mathrm{min}$ and column temperature was maintained at $40^{\circ} \mathrm{C}$. Insulin loading and entrapment efficiency were calculated by using the following formulas [10]:

$$
\begin{aligned}
& \text { \%Entrapment efficiency } \\
& =\left[\frac{\text { Total amount of insulin-Free amount of insulin }}{\text { Total amount of insulin }}\right] \times 100, \\
& \% \text { Loading capacity } \\
& =\left[\frac{\text { Total amount of insulin-Free amount of insulin }}{\text { Weight of nanoparticle }}\right] \times 100 \text {. }
\end{aligned}
$$

2.3.4. Insulin In Vitro Release from Nanoparticles. Insulin in vitro release from insulin loaded nanoparticles was determined in the first phase using Hydrochloric acid buffer, $\mathrm{pH}$ 1.2 and in the second phase using phosphate buffer, $\mathrm{pH}$ 6.8. At determined time intervals, $0.4 \mathrm{~mL}$ of supernatant was taken, separated from nanoparticles by centrifugation $(20,000 \times \mathrm{g} / 30 \mathrm{~min})$ and analyzed by HPLC for determination of insulin concentration present free in the supernatant and replaced by fresh medium. Release assays were performed in triplicate [11].

2.3.5. In Vivo Pharmacological Studies. Fasting blood glucose was determined after depriving food for $16 \mathrm{hrs}$ with free access of drinking water. Streptozotocin was freshly dissolved in $0.1 \mathrm{M}$ citrate buffer $(\mathrm{pH}=4.5)$ at the dose of $60 \mathrm{mg} / \mathrm{kg}$ 
body weight and injected intraperitoneally. Blood glucose level was estimated at $0 \mathrm{hr}$ and repeated after a gap of $1 \mathrm{hr}$ of experiment with the help of glucometer using glucose strip method and blood was taken from tail tip of the rat [12]. Rats having blood glucose level more than $250 \mathrm{mg} / \mathrm{dL}$ were separated and divided into six different groups comprising of 6 rats in each group for the antidiabetic study. The different groups were administered as follows. First group was administered with only distilled water, second group was administered intragastrically with placebo nanoparticles dispersed in $0.5 \mathrm{~mL}$ purified water, third group was administered with $5 \mathrm{IU} / \mathrm{Kg}$ insulin solution intragastrically, fourth group was administered with $10 \mathrm{IU} / \mathrm{Kg}$ insulin loaded nanoparticle dispersed in $0.5 \mathrm{~mL}$ purified water intragastrically, and the fifth group was administered subcutaneously with human insulin injection at a dose of $5 \mathrm{IU} / \mathrm{Kg}$. During the period of antidiabetic study, animals in all groups had free access to standard diet and water. Blood glucose level was estimated at $0 \mathrm{hr}$ and repeated after a gap of $1 \mathrm{hr}$ of experiment with the help of glucometer using glucose strip method and blood was taken from tail tip of the rat. Diabetes is characterized by body weight loss and it was also seen in the present study. After treatment with streptozotocin body weight was taken with the help of single pan balance at an interval of 3 days up to 10 days. The treated animals were also weighed using a single pan balance and compared with diabetic rats.

2.3.6. Determination of Serum Human Insulin and Biochemical Parameters. One $\mathrm{mL}$ of blood collected from the treated rat was directly taken into a serum tube without an anticoagulant. The blood was left at room temperature for $30 \mathrm{~min}$ to clot. The clotted blood sample was centrifuged at $3,000 \mathrm{RPM}$ for $15 \mathrm{mins}$ at $4 \pm 2^{\circ} \mathrm{C}$. The supernatant serum samples were collected in separate tubes. According to the protocol of human insulin ELISA kit the samples were prepared. Absorbance was determined at $450 \mathrm{~nm}$ wave length using a spectrophotometer after adjusting final volume of each sample to $2 \mathrm{~mL}$ using distilled water [13].

Biochemical parameters notably, total cholesterol (TC), urea, creatinine, and protein levels in blood serum were measured spectrophotometrically [14].

2.3.7. Pharmacokinetic Evaluation. The pharmacokinetic calculations were based on individual plasma concentrationtime data. The maximum plasma concentration $\left(C_{\max }\right)$ and the time at which it occurred $\left(t_{\max }\right)$ were determined. The bioavailability $(F)$ was determined by using the formula given below, corrected for the dose. Each individual per oral exposure was compared with the mean. Pharmacological bioavailability was calculated by the following formula [15]:

$$
F=\frac{\mathrm{AAC}_{\text {oral }} \times \text { Dose }_{\text {parenteral }}}{\mathrm{AAC}_{\text {parenteral }} \times \text { Dose }_{\text {oral }}} \text {. }
$$

\section{Results and Discussion}

3.1. Characterization of Insulin Loaded Nanoparticles. From particle size analysis data it was found that insulin incorporation increases particle size of nanoparticles as com-
TABLE 1: Physicochemical properties of insulin loaded nanoparticles.

\begin{tabular}{lcc}
\hline Insulin concentration $(\mathrm{IU} / \mathrm{mL})$ & Parameters & Mean \pm SD \\
\hline \multirow{4}{*}{10} & Particle size $(\mathrm{nm})$ & $551.67 \pm 45.5$ \\
& Zeta potential $(\mathrm{mV})$ & $25.70 \pm 02.67$ \\
& PDI & $00.20 \pm 00.06$ \\
\hline
\end{tabular}

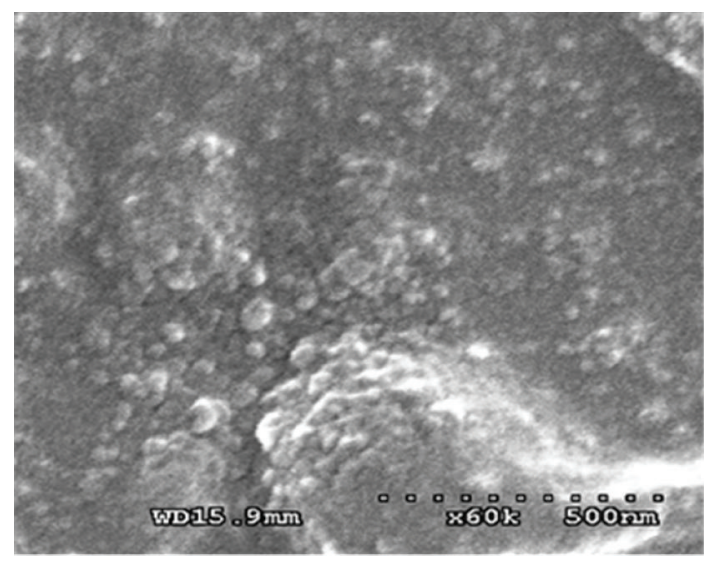

FIGURE 1: SEM image of $10 \mathrm{IU} / \mathrm{mL}$ of insulin incorporated nanoparticles.

pared to empty nanoparticles. The nanoparticles loaded with $10 \mathrm{IU} / \mathrm{mL}$ insulin were found to have an average particle size of $551.67 \mathrm{~nm} \pm 45.5$ (Table 1).

The SEM image of $10 \mathrm{IU} / \mathrm{mL}$ insulin loaded nanoparticles was observed as solid spheres (Figure 1).

The particle size from SEM image was shown to be smaller than the particle size determined by dynamic light scattering method. The decrease in particle size might be due to preparation of slides of the sample for analysis by SEM in dry state decreasing the particle size whereas in wet state increasing size of the nanoparticles by dynamic light scattering method. The FT-IR spectrum of insulin was found to have two characteristic absorption peaks one at $1664 \mathrm{~cm}-1$ for amide I and another at $1531.63 \mathrm{~cm}-1$ corresponding to amide II mainly due to $\mathrm{C}=\mathrm{O}$ stretching vibration characteristic of protein spectrum [11]. However, in the spectrum of insulin loaded nanoparticle, the two characteristic absorption peaks of insulin were almost masked and a new peak at $1598.88 \mathrm{~cm}^{-1}$ was formed. Moreover, no new peaks were observed in the FT-IR spectrum of insulin loaded nanoparticles (Figure 2).

These observations suggest that some weak physical interactions between insulin and the polymers complex between chitosan and alginate were formed during the formation of the insulin loaded nanoparticles.

\subsection{Loading and Entrapment Efficiency of Insulin Loaded} Nanoparticles. As the concentration of loaded insulin increased entrapment efficiency was decreased, with highest entrapment efficiency value of $52.48 \pm 1.98$ for $5 \mathrm{IU} / \mathrm{mL}$ insulin loaded nanoparticle and lowest entrapment value of $22.35 \pm 1.59$ for $50 \mathrm{IU} / \mathrm{mL}$ insulin loaded nanoparticle. The loading capacity had shown a reverse behavior as compared 


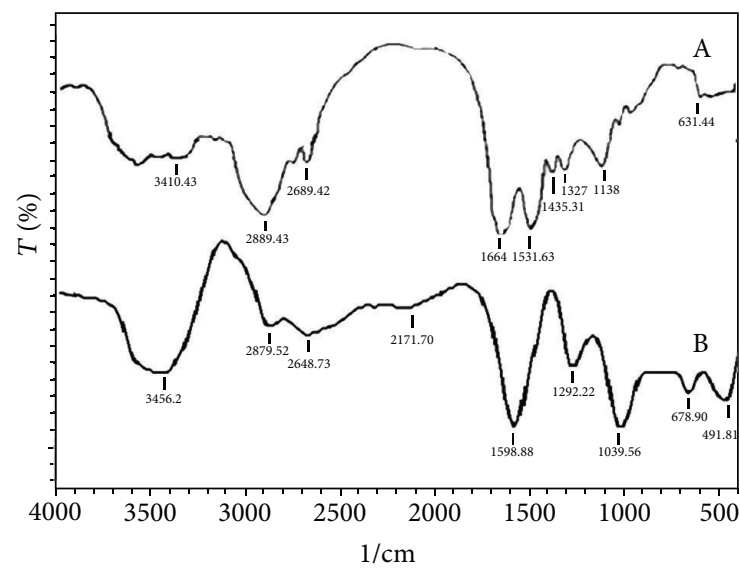

FIGURE 2: FT-IR spectrum of (A): normal human insulin, (B): insulin loaded nanoparticles.

TABLE 2: Entrapment and loading percentage of insulin loaded nanoparticles.

\begin{tabular}{lcc}
\hline $\begin{array}{l}\text { Insulin concentration } \\
(\mathrm{IU} / \mathrm{mL})\end{array}$ & $\begin{array}{c}\text { Mean \% entrapment } \\
\text { efficiency } \pm \mathrm{SD}\end{array}$ & $\begin{array}{c}\text { Mean \% loading } \\
\pm \mathrm{SD}\end{array}$ \\
\hline 05 & $52.48 \pm 1.98$ & $19.64 \pm 1.48$ \\
10 & $43.43 \pm 1.86$ & $25.07 \pm 0.57$ \\
20 & $38.00 \pm 0.33$ & $31.33 \pm 0.87$ \\
30 & $31.01 \pm 0.71$ & $36.27 \pm 1.23$ \\
40 & $24.40 \pm 1.37$ & $42.80 \pm 0.87$ \\
50 & $22.35 \pm 1.59$ & $47.01 \pm 1.21$ \\
\hline
\end{tabular}

to entrapment efficiency. Higher concentration of insulin used was having higher loading capacity and vice versa. The highest loading capacity value was shown to be $47.01 \pm 1.21$ for $50 \mathrm{IU} / \mathrm{mL}$ insulin loaded nanoparticle and lowest loading capacity value was shown to be $19.64 \pm 1.48$ for $5 \mathrm{IU} / \mathrm{mL}$ insulin loaded nanoparticles data shown in Table 2.

3.3. In Vitro Release Study of Insulin from Loaded Nanoparticles. Concentration of insulin released from $10 \mathrm{IU} / \mathrm{mL}$ insulin loaded nanoparticle was presented in Table 3. In the first 15 mins there was a large amount of insulin released in the acidic medium; the release was going on decreasing as time of incubation increased. Once again when the samples transferred to phosphate buffer after 120 mins, in the first time frame there was maximum release that goes on decreasing as the time increased and reached to a minimum at 300 mins. The release kinetics study was carried out by Korsmeyer's equation and the $n$ value was found to be 0.18 ; therefore, the release behaviour was a combination of both diffusion and erosion controlled release [16].

3.4. In Vivo Antidiabetic Study. The antidiabetic study of orally administered insulin loaded nanoparticles in diabetes induced rats showed interesting results by decreasing the blood glucose to a lower level and the hypoglycemic effect remains for a longer period of time than insulin administered through parenteral route.
3.5. Lowering of Blood Glucose. Percentage base level blood glucose change of diabetic rats after administration of saline solution only $(\mathrm{Gr} 1)$ and placebo nanoparticles equivalent to $10 \mathrm{IU} / \mathrm{Kg}(\mathrm{Gr} 2)$ did not show any significant decrease whereas administration of insulin solution $10 \mathrm{IU} / \mathrm{Kg}$ orally ( $\mathrm{Gr} 3$ ) showed a little decrease in blood glucose starting from second time point to $16 \mathrm{hrs}$. Percentage base level blood glucose change of diabetic rats after administration of $10 \mathrm{IU} / \mathrm{Kg}$ of insulin loaded nanoparticles orally (Gr 4) showed a decrease in blood glucose of experimental animals to a significant level starting from second time point reaching a peak change of mean \pm SD of $53.46 \pm 2.19$ at 5-hour interval and afterwards blood glucose levels increased. Percentage base level blood glucose change of diabetic rats after administration of $5 \mathrm{IU} / \mathrm{Kg}$ of insulin as subcutaneous injection (Gr 5) had shown a significant decrease in blood glucose level of mean \pm SD of $18.83 \pm 0.64$ at $2 \mathrm{hrs}$ time point that was very less as compared to insulin loaded nanoparticles. The blood glucose levels increased afterwards and the decrease level was maintained up to $14 \mathrm{hrs}$. The mean percentage blood glucose change along with the standard deviations for all the different treatments was shown in Table 4 . These raised levels of blood glucose in diabetic rats were declined sharply after oral feeding of insulin loaded nanoparticle. This decline in blood glucose levels of drug treated groups when compared with their respective diabetic control group was found to be highly statistically significant $(P<0.001)$. Percentage pharmacological bioavailability of $10 \mathrm{IU} / \mathrm{Kg}$ insulin loaded nanoparticles was found to be 43.60 [17].

3.6. Determination of Body Weight. Diabetes is characterized by body weight loss and it was also observed in the present study as shown in Table 5. Streptozotocin administration brought about marked reduction in body weight of experimental animals. These reduced body weights of experimental animals were found to be increased after administration of insulin loaded nanoparticle.

3.7. Determination of Serum Human Insulin. The serum insulin concentration was more in case of $5 \mathrm{IU} / \mathrm{Kg}$ of insulin injection as compared to $10 \mathrm{IU} / \mathrm{Kg}$ of insulin loaded nanoparticles, but an average level was maintained for a long period of time in case of $10 \mathrm{IU} / \mathrm{Kg}$ of insulin loaded nanoparticles. That indicates that the nanoparticulate system act as a barrier for the incorporated insulin thereby sustains the availability of insulin for a longer period of time. The change in biochemical parameters of diabetic rats was returned to normalcy after administration with $10 \mathrm{IU} / \mathrm{Kg}$ of insulin loaded nanoparticles confirming insulin incorporated nanoparticles very much useful for treatment of diabetes after oral administration.

3.8. Pharmacokinetic Evaluation. The maximum plasma concentration $\left(C_{\max }\right)$ and the time at which it occurred $\left(t_{\max }\right)$ were shown in Table 6 . The percentage pharmacological bioavailability of $10 \mathrm{IU} / \mathrm{Kg}$ of insulin loaded nanoparticles after oral administration as compared with $5 \mathrm{IU} / \mathrm{Kg}$ of insulin injection was found to be 43.60 . 
TABle 3: Percentage cumulative release study of insulin loaded nanoparticles in different buffer systems.

\begin{tabular}{|c|c|c|c|c|c|c|c|c|c|}
\hline Buffers & & HCL buff & er $\mathrm{pH}=1.2$ & & & Phosp & hate buffer $\mathrm{pl}$ & $\mathrm{H}=6.8$ & \\
\hline Time (min) & 015 & 030 & 060 & 120 & 135 & 150 & 180 & 240 & 300 \\
\hline $\begin{array}{l}\text { Mean } \% \\
\text { cumulative } \\
\text { release } \pm \text { SD }\end{array}$ & $37.91 \pm 0.71$ & $46.48 \pm 1.06$ & $49.09 \pm 0.75$ & $50.78 \pm 0.76$ & $57.09 \pm 0.26$ & $62.35 \pm 2.04$ & $64.10 \pm 1.12$ & $65.42 \pm 0.35$ & $66.06 \pm 0.09$ \\
\hline
\end{tabular}

TABLE 4: Mean blood glucose change (\% base level) \pm SD of diabetic rats after different treatments.

\begin{tabular}{|c|c|c|c|c|c|c|c|c|c|c|}
\hline \multirow{2}{*}{ Treatment } & \multicolumn{10}{|c|}{ Blood glucose change (\% base level) of diabetic rats at different time intervals (Mean \pm SD) } \\
\hline & $0 \mathrm{hr}$ & $1 \mathrm{hr}$ & $2 \mathrm{hrs}$ & $3 \mathrm{hrs}$ & $4 \mathrm{hrs}$ & $5 \mathrm{hrs}$ & $6 \mathrm{hrs}$ & $10 \mathrm{hrs}$ & $14 \mathrm{hrs}$ & $18 \mathrm{hrs}$ \\
\hline Gr 1 & $100 \pm 00$ & $\begin{array}{c}105.51 \pm \\
3.47\end{array}$ & $\begin{array}{c}104.05 \pm \\
1.77\end{array}$ & $\begin{array}{c}106.27 \pm \\
4.45\end{array}$ & $\begin{array}{c}105.74 \pm \\
4.38\end{array}$ & $\begin{array}{c}102.51 \pm \\
5.43\end{array}$ & $\begin{array}{c}107.21 \pm \\
1.97\end{array}$ & $\begin{array}{c}104.28 \pm \\
3.70\end{array}$ & $\begin{array}{c}107.21 \pm \\
2.88\end{array}$ & $105.59 \pm 6.59$ \\
\hline Gr 2 & $100 \pm 00$ & $\begin{array}{c}103.13 \pm \\
7.17\end{array}$ & $\begin{array}{c}102.75 \pm \\
4.58\end{array}$ & $\begin{array}{c}102.89 \pm \\
4.17\end{array}$ & $\begin{array}{c}103.17 \pm \\
3.59\end{array}$ & $\begin{array}{c}101.66 \pm \\
5.14\end{array}$ & $\begin{array}{c}104.48 \pm \\
4.59\end{array}$ & $\begin{array}{c}101.93 \pm \\
6.66\end{array}$ & $\begin{array}{c}100.25 \pm \\
7.84\end{array}$ & 102.75 \\
\hline Gr 3 & $100 \pm 00$ & $\begin{array}{c}98.55^{*} \pm \\
1.28\end{array}$ & $\begin{array}{c}95.08^{* * *} \pm \\
2.41\end{array}$ & $\begin{array}{c}93.86^{* * *} \pm \\
2.40\end{array}$ & $\begin{array}{c}93.51^{* * *} \pm \\
3.42\end{array}$ & $\begin{array}{c}95.50 \pm \\
2.44\end{array}$ & $\begin{array}{c}97.73^{*} \pm \\
1.66\end{array}$ & $\begin{array}{c}98.09 \pm \\
1.67\end{array}$ & $\begin{array}{c}99.33 \pm \\
2.97\end{array}$ & $101.12 \pm 3.10$ \\
\hline Gr 4 & $100 \pm 00$ & $\begin{array}{c}74.90^{* * *} \pm \\
4.14\end{array}$ & $\begin{array}{c}64.26^{* * *} \pm \\
3.70\end{array}$ & $\begin{array}{c}60.15^{* * *} \pm \\
3.10\end{array}$ & $\begin{array}{c}57.74^{* * *} \pm \\
2.81\end{array}$ & $\begin{array}{c}53.46^{* * *} \pm \\
2.19\end{array}$ & $\begin{array}{c}56.50^{* * * *} \pm \\
2.28\end{array}$ & $\begin{array}{c}73.20^{* * *} \pm \\
5.91\end{array}$ & $\begin{array}{c}90.52^{* * * *} \pm \\
5.02\end{array}$ & $101.79 \pm 1.49$ \\
\hline Gr 5 & $100 \pm 00$ & $\begin{array}{c}26.43^{* * *} \pm \\
1.30\end{array}$ & $\begin{array}{c}18.83^{* * *} \pm \\
0.64\end{array}$ & $\begin{array}{c}38.02^{* * *} \pm \\
3.66\end{array}$ & $\begin{array}{c}52.00^{* * *} \pm \\
3.94\end{array}$ & $\begin{array}{c}65.95^{* * *} \pm \\
4.03\end{array}$ & $\begin{array}{c}74.91^{* * *} \pm \\
1.49\end{array}$ & $\begin{array}{c}86.72^{* * *} \pm \\
3.10\end{array}$ & $\begin{array}{c}97.01^{* *} \pm \\
2.91\end{array}$ & $102.13 \pm 2.22$ \\
\hline
\end{tabular}

${ }^{*} P<0.05,{ }^{* *} P<0.01,{ }^{* * *} P<0.001$ when compared with control.

TABLE 5: Body weight change of normal, diabetic and insulin loaded nanoparticle treated rats over a period of 10 days.

\begin{tabular}{lccc}
\hline $\begin{array}{l}\text { Time } \\
(\text { days })\end{array}$ & $\begin{array}{c}\text { Normal control } \\
\text { Body weight } \\
(\text { gms }) \pm \text { SD }\end{array}$ & $\begin{array}{c}\text { Diabetic control } \\
\text { Body weight } \\
(\text { gms }) \pm \text { SD }\end{array}$ & $\begin{array}{c}\text { Diabetic treated } \\
\text { with insulin loaded } \\
\text { Nanoparticle body } \\
\text { weight }(\mathrm{gms}) \pm \text { SD }\end{array}$ \\
\hline 01 & $202.19 \pm 16.23$ & $198.96 \pm 20.39$ & $197.68 \pm 13.45$ \\
04 & $205.58 \pm 14.84$ & $168.99 \pm 18.21$ & $191.47 \pm 14.86$ \\
07 & $208.60 \pm 14.07$ & $148.23 \pm 18.40$ & $182.34 \pm 16.64$ \\
10 & $213.40 \pm 12.73$ & $137.51 \pm 17.89$ & $177.57 \pm 15.76$ \\
\hline
\end{tabular}

TABLE 6: Value of pharmacokinetic parameters for human insulin in serum of rats administered with different types of insulin preparations.

\begin{tabular}{lcc}
\hline Parameters & $\begin{array}{r}5 \mathrm{IU} / \mathrm{Kg} \text { insulin } \\
\text { injection }\end{array}$ & $\begin{array}{c}\text { 10 IU/Kg insulin } \\
\text { loaded nanoparticles }\end{array}$ \\
\hline$C_{\max }(\mu \mathrm{IU} / \mathrm{mL})$ & 111.57 & 027.69 \\
$T_{\max }(\mathrm{hr})$ & 002.00 & 005.00 \\
\hline
\end{tabular}

\section{Conclusions}

The insulin incorporated nanoparticles were prepared efficiently by complex coacervation technique using the biodegradable polymers chitosan and sodium alginate. The absolute bioavailability in rats was determined for a single dose of $10 \mathrm{IU} / \mathrm{kg}$ of insulin incorporated nanoparticle administered orally. The oral bioavailability of insulin obtained in this study was found to be less than $50 \%$ as compared to subcutaneous delivery, but the action was sustained for a long period of time around $5 \mathrm{hrs}$ as compared to $2 \mathrm{hrs}$ in case of parenteral insulin administration. The results of this study reveal the potential of nanoparticulate system prepared by hydrophilic and biodegradable polymers for oral delivery of insulin. However more detailed studies have yet to be done to reveal the mechanisms of drug absorption and further improvement of the system to boost insulin absorption efficiency.

\section{Acknowledgments}

The authors are thankful to the management of Institute of Pharmacy and Technology, Salipur, Cuttack, Odisha and staff of UDPS, Utkal University for their support and generosity.

\section{References}

[1] A. K. Prusty and S. K. Sahu, "Newer approaches for insulin administration in diabetes treatment," Pharmacologyonline, vol. 2, pp. 852-861, 2009.

[2] F. Cui, K. Shi, L. Zhang, A. Tao, and Y. Kawashima, "Biodegradable nanoparticles loaded with insulin-phospholipid complex for oral delivery: preparation, in vitro characterization and in vivo evaluation," Journal of Controlled Release, vol. 114, no. 2, pp. 242-250, 2006.

[3] H. S. Kaş, "Chitosan: properties, preparations and application to microparticulate systems," Journal of Microencapsulation, vol. 14, no. 6, pp. 689-711, 1997.

[4] C.-M. Lehr, J. A. Bouwstra, E. H. Schacht, and H. E. Junginger, "In vitro evaluation of mucoadhesive properties of chitosan and some other natural polymers," International Journal of Pharmaceutics, vol. 78, no. 1, pp. 43-48, 1992.

[5] N. G. M. Schipper, S. Olsson, J. A. Hoogstraate, A. G. DeBoer, K. M. Vårum, and P. Artursson, "Chitosans as absorption enhancers for poorly absorbable drugs 2 : mechanism of absorption enhancement," Pharmaceutical Research, vol. 14, no. 7, pp. 923-929, 1997. 
[6] D. E. Chickering III, J. S. Jacob, T. A. Desai et al., "Bioadhesive microspheres: III. An in vivo transit and bioavailability study of drug-loaded alginate and poly (fumaric-co-sebacic anhydride) microspheres," Journal of Controlled Release, vol. 48, no. 1, pp. 35-46, 1997.

[7] W. R. Gombotz and D. K. Pettit, "Biodegradable polymers for protein and peptide drug delivery," Bioconjugate Chemistry, vol. 6, no. 4, pp. 332-351, 1995.

[8] S. Kumar Sahu and A. Kumar Prusty, "Design and evaluation of a nanoparticulate system prepared by biodegradable polymers for oral administration of protein drugs," Pharmazie, vol. 65, no. 11, pp. 824-829, 2010.

[9] Z. Wu, Q. Ping, Y. Wei, and J. Lai, "Hypoglycemic efficacy of chitosan-coated insulin liposomes after oral administration in mice," Acta Pharmacologica Sinica, vol. 25, no. 7, pp. 966-972, 2004.

[10] Z. Ma, T. M. Lim, and L. Lim, "Pharmacological activity of peroral chitosan-insulin nanoparticles in diabetic rats," International Journal of Pharmaceutics, vol. 293, no. 1-2, pp. 271-280, 2005.

[11] B. Sarmento, A. Ribeiro, F. Veiga, and D. Ferreira, "Development and characterization of new insulin containing polysaccharide nanoparticles," Colloids and Surfaces B: Biointerfaces, vol. 53, no. 2, pp. 193-202, 2006.

[12] M. A. Radwan and H. Y. Aboul-Enein, "The effect of oral absorption enhancers on the in vivo performance of insulinloaded poly(ethylcyanoacrylate) nanospheres in diabetic rats," Journal of Microencapsulation, vol. 19, no. 2, pp. 225-235, 2002.

[13] R. Golla and R. Seethala, "A sensitive, robust high-throughput electrochemiluminescence assay for rat insulin," Journal of Biomolecular Screening, vol. 9, no. 1, pp. 62-70, 2004.

[14] V. H. Talib, A Hand Book of Medical Laboratory Technology, CBS publishers \& Distributors, New Delhi, India, 2009.

[15] P. S. Singnurkar and S. K. Gidwani, "Evaluation of hydrophobic nanoparticulate delivery system for insulin," Indian Journal of Pharmaceutical Sciences, vol. 70, no. 6, pp. 721-726, 2008.

[16] M. C. Gohel, M. K. Panchal, and V. V. Jogani, "Novel mathematical method for quantitative expression of deviation from the Higuchi model," AAPS PharmSciTech, vol. 1, no. 4, article 31, 2000.

[17] Y. Pan, J. Zheng, H. Zhao, Y. Li, H. Xu, and G. Wei, "Relationship between drug effects and particle size of insulin-loaded bioadhesive microspheres," Acta Pharmacologica Sinica, vol. 23, no. 11, pp. 1051-1056, 2002. 

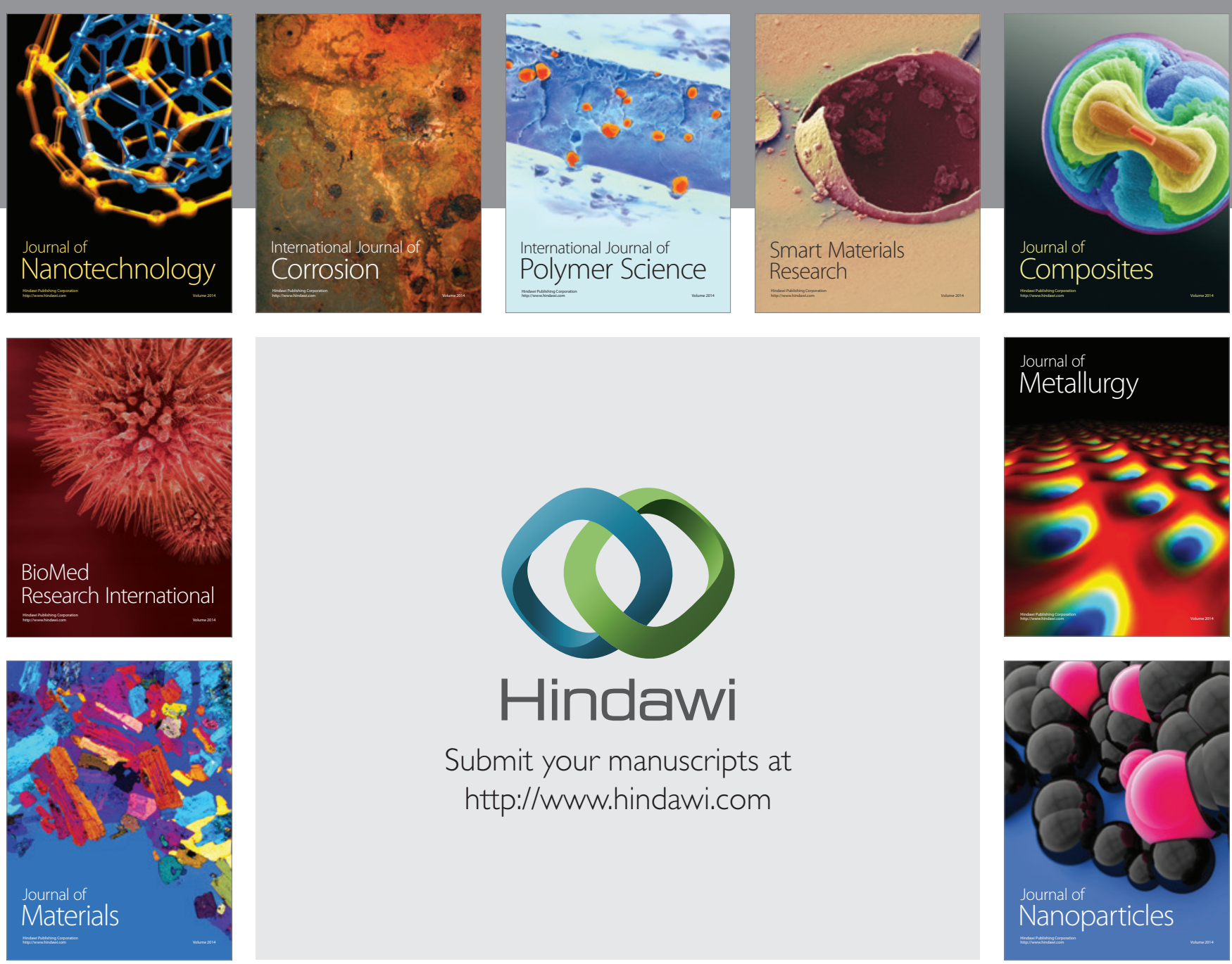

Submit your manuscripts at http://www.hindawi.com
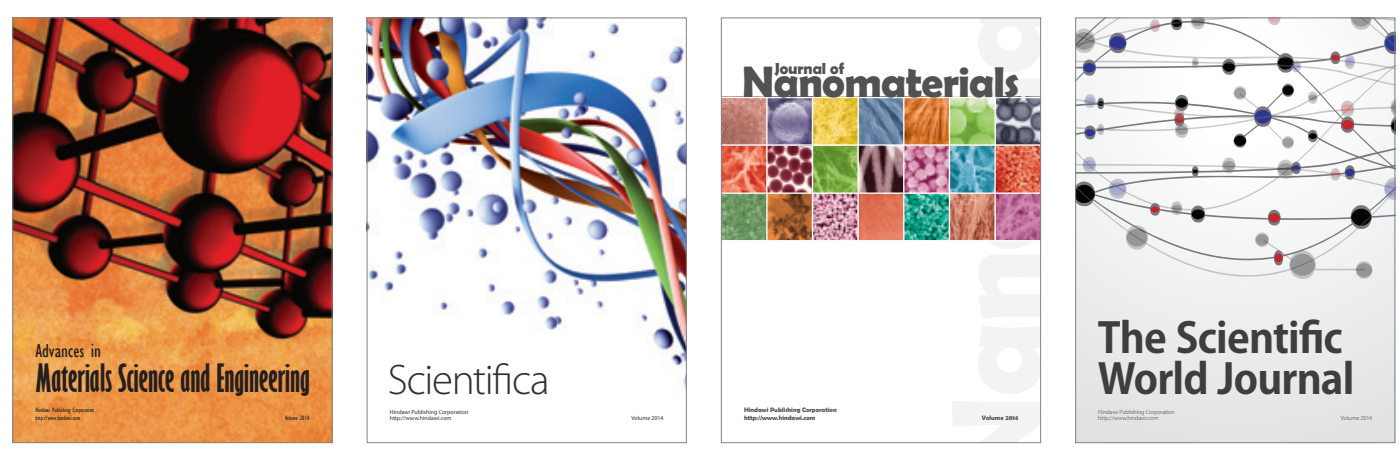

\section{The Scientific World Journal}
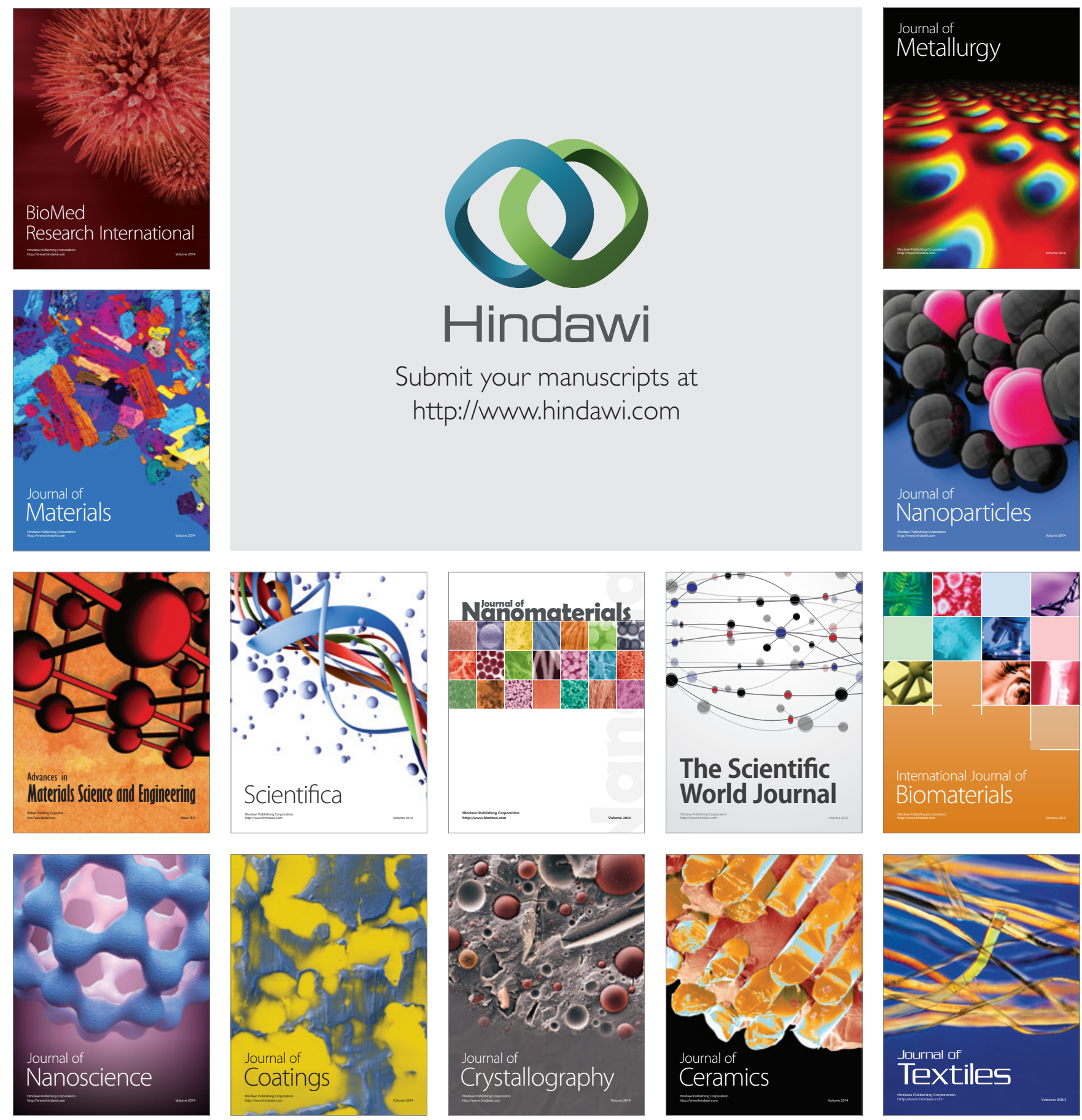